\title{
Calderón de la Barca, o el Sueño y la Esencia de la Vida.
}

\author{
(Sintesis de una Conferencia)
}

Se ha repetido siempre, y conviene expresarlo una vez més zhora, que Lope de Vega y Calderón de la Barca son los dos firmes polos entre los que gíra todo el teatro español en la llamada con razón Edad de Oro de las letras en lenqua castellana. Tempestuoso, genial, despilfarrado el uno; grave, profundo, reflexivo el otro. Espontáneo, vìvaz, cálido Lope, como un prodigio de la Naturaleza ("monstruo de la Naturaleza", lleqó a decir precisamente de él el propio Cervantes). Thascendente, meditativo, con una alta y profunda majestad el ilustre Don Pedro Calderón de la Barcau J SeghaPdichoirtambién quelelcteatro de Lope (madurado en el imperial y creador siglo XVI) es la España que se refleja. Y se pinta a sí misma, en tanto que el teatro de Calderón (curralore del barroco siglo XVII) es la España que se medita y se piensa a sí misma; y es verdad. En la obra de Calderón no sólo hay entretenimiento y belleza formal. Su teatro - y es éste el título más alto y más perranente de su gloria - alcanza también los problemas de la vida y la muerte, de la responsabilidad y el destino del hombre.

\section{"LA VIDA ES SUENTO"}

Tal es el caso de "La vida es sueño". Doña Blanca de los Pálos de Lampérez escribió hace unos años que los cinco mayores mitos, las cinco grandes creaciones literarias de la Edad Moderna son: Dor Quijote, Don Juan, Hamlet, Segismundo (el protagonista de "La vida es sueño") y Fausto. Y aunque el personaje de Calderón no tiene, en realidad, tanta resonancia universal ni ha forjado progenie tan itustre co- 
mo los otros ejregios personajes, la grandeza de su concepción y lo profundo de su peisamiento justifican que se le incluya en esa lista gloriosa de elegidos.

Para halago y orgullo de España, tres de esos cinco grandes nombres son creaciones españolas (si es que no hay que citar además un sexto; porque Ion Quijote no está completo sin lo que se podría llamar su contraparte, su fiel y también admirable e insigne escudero Sancho Panza). En tres de ellos se presenta también sobre la escena el hondo tena de la duda íntima y de la angustía tremenda del hombre. Pálido y enlutado, el Príncipe de Dinamarca se debate en el borde mismo de esa zona angustiosa entre el ser. y el no ser. El pesonaje de Goethe padece del choque insuperable entre sus aspiraciones infinitas y sus poderes finitos de hombre. Segismundo, el héroe de Calderón, también duda, también vacila entre el sueño y la realidad, entre la ilusión de los sentidos y la esencia profunda de la vida. Pero su respuesta es luego afirmativa, por católica y por española al propio tiempo.

En la España, del siglo XVII los hombres tenían que confiar y afirmar; porque los Hamiets vacilantes sólo podían ser, al fin y al cabo - como en el título de la obra atribuída a Tírso de Molina -, "condenados por desconfiados".

\section{DATOS DEL ARGUMENTO}

El argumento de "La vida es sueño" es conocido. Basilio, Rey de Polonia, dado a consuler Pascastrosl (quelson lpara él las letras de los 'cuadernos de zaftro' donde se hallan escritas nuestras vidas), llega a la dolorosa conclusión de que su hijo el Príncipe Segismundo ha nacido con el horóscopo más adverso. Las estrellas le dicen que Segismundo será un tirano cruel, atrevido e impío. Por eso resuelve criarlo fuera de la Corto, escondido entre bosques y entre riscos, al cuidado de un ayo, el leal Clotaldo. Pero cuando avanzan los años, y Basilio quiere decidir la sucesión al trono, imagina un recurso para que terminen los escrúpulos que en el fondo de su conciencia le atormentan: dar ur narcótico a Segismundo y llevarle, bruscamente, a la Corte para que ocupe por un día el sitio reai. Ei Segismundo actúa bien, las estrellas se habrán equivocado. Si en cambio, es tan violento y malvado como se teme, se le conducirá de nuevo, y ya definitivamente, a su caverna.

Ia prueba, por desgracia, se realiza con caracteres lamentables. Segismundo, al saberse hijo de Rey, arremete contra Clotaldo, arroja por un baicón a un crjado que le contradice, ofende a su propio padre, quie- 
re atropellar el honor de Rosaura. No queda sino volverle a dar un bebedizo y llevarlo a su prisión. Pero al despertar otra vez con pieies y cadenas, en lugar de los trajes suntuosos y las aduladoras galas del Palacio, Segismundo, inesperadamente, reacciona. La conmoción espiritual que le producen tales cambios le obliga a pensar y a meditar. Entonces comprende que toda la vida es sueño; que hay fantasmas y engaños transitorios; que es necesario reprimir la soberbia, porque el sueño galano se puede desvanecer en cualquier instante. Comprende también que lo fundamental es obrar bien, y desentrañar los valores esen. ciales hundidos en la sensible y falaz apariencia.

Entre tanto, el pueblo de Polonia se ha enterado de los sucesos. Re clamando por Rey a Segismundo marcha una multitud hasta su cueva; y le fuerzan a encabezar una rebelión, más que contra Basilio, contra el supuesto sucesor Astolfo. Los cortesanos, desde luego, se alarman; pero, ante la satisfecha sorpresa de todos, Segismundo, al llegar al mando, vencedor de sí mismo, actúa con nobleza, ponderación y justicia ejemplares.

\section{LOS TRES ASPECTOS DE "LA VIDA ES SUEÑO"}

Analicemos ahora, sobre la base de este argumento (y dejando de lado la excelencia teatral, la calidad poética, y los méritos o las deficiencias de la forma), el pensamiento capital de este drama genial de Calderón.

\section{Biblioteca de Letras}

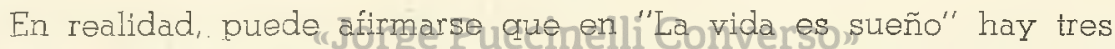
aspectos, cada uno de los cuales tiene su cabal expresión en determinados versos de la obra.

\section{EL ASPECTO ESCEPTICO}

En primer lugar, el ilusionismo, el aspecto del engaño mañoso, del sueño y del fingimiento de la vida. Es, por cierto, un problema que no se origina en Calderón; sino que hunde sus raíces en los antiguos campos de las literaturas orientales. Investigándolo, tanto desde el punto de vista del fondo mismo cuanto de la forma como se ha llevado el tema al drama, los críticos han encontrado dos antecedentes o dos fuentes.

A) - En cuanto a la forma, el tema del hombre recluído en la cue$\mathrm{va}$ como consecuencia de un horóscopo adverso. El ejemplo seguido por Calderón se cree que puede hallarse en' el célebre "Barlaam y Josafat", transformación cristiana de la leyenda de Buda, emparentada con el "Lalita Vistara" tibetano, y cuyo texto griego, de tan extraordinaria 
influencia en la literatura de Occidente tué obra de un monje sirio o palestino, aunque se atribuyó por mucho tiempo a San Juan Damasceno. Allí aparece el encierro del Príncipe, para impedir el cumplimiento de una predicción leída en los astros.

Este tema pudo vincularse más tarde con el muy común de los anaccretas, de los adustos ermitaños que vivían llenos de mortificaciones en el yermo, con un santo terror de los engaños sensoriales del mundo. A Calderón, además, llega el asunto decorado por la escenografía barroca del hombre natural; que no es precisamente el "bon sauvage" de los románticos, sino por el contrario el hombre bárbaro, monstruo sưieto a los instintos, en oposición al hombre civil, el hombre urbano, guiado por la luz de la razón. El fuerte contraste se concreta en la oposición monte-Palacio. Por los escenarios del siglo XVII desfila una teoría de seres solitarios, que viven entre peñas, riscos abruptos y cavernas, en buscà de una verdad más sustancial y más perfecta.

Esos seres abundan, reveladoramente, en la producción calderoniana. Se trata así, no de uno elaboráción ocasional, sino de un pensamiento persistente. Doña Blanca de los Ríos ha señalado diez personajes semejantes, antre varones y mujeres (a los cuales Farinelli ha agregado una más, en su magitsral estudio sobre "La vida es sueño"), que llegan hasta la última comedia de Don Pedro Calderón: "Hado y divisa de Leónido y de Marfisa", compuesta en 1680, o sea un año antes de la muerte de su autor.blioteca de Letras

B) - En cuanto al fondo mismo hay otro tema que también recoge Calderón del rico y viejo acervo de las literaturas orientales. Es el tema del sueño, como símbolo de la indecisión entre el engaño y la verdad, entre lo ilusión y la realidad, la ficción y la vida. El ejemplo preciso más antíquo parece ser el cuento del "durmiente despierto", incorporado a la colección árabe de las "Mil y una noches", donde ocupa las noches 623 a 653. Se trata del ameno y burlón episodio de Abul-Hassán, el Disoluto, a quien el Emir de los Creyentes, el poderoso Harúnal-Raschid, haco dormir mediante un narcótico y por varias horas le lleva a creer que es el propio Emir. El cuento fué recibiendo nuevas formas en su largo trayecto a través de las literaturas. En España, la más antigua es la versión trunca añadida a "El Conde Lucanor" de Don Juan Manuel, en el códice que fué del Conde de Puñonrrostro; y a principios del siglo XVII hay otra versión equivalente en el "Viaje entretenido" de Agustín de Rojas.

Pero lo que era simple burla, episodio sonriente, se torna gravedad y frunce el ceño en una epístola de Luis Vives al Duque de Béjar, que 
re atropellar el honor de Rosaura. No queda sino volverle a dar un bebedizo y llevarlo a su prisión. Pero al despertar otra vez con pieies y cadenas, en lugar de los trajes suntuosos y las aduladoras galas del Palacio, Segismundo, inesperadamente, reacciona. La conmoción espiritual que le producen tales cambios le obliga a pensar y a meditar. Entonces comprende que toda la vida es sueño; que hay fantasmas y engaños transitorios; que es necesario reprimir la soberbia, porque el sueño galano se puede desvanecer en cualquier instante. Comprende también que lo fundamental es obrar bien, y desentrañar los valores esenciales hundidos en la sensible y falaz apariencia.

Entre tanto, el pueblo de Polonia se ha enterado de los sucesos. Reclamando por Rey a Segismundo marcha una multitud hasta su cueva; y le fuerzan a encabezar una rebelión, más que contra Basilio, contra el supuesto sucesor Astolfo. Los cortesanos, desde luego, se alarman; pero, ante la satisfecha sorpresa de todos, Segismundo, al llegar al mando, vencedor de sí mismo, actúa con nobleza, ponderación y justicia ejemplares.

\section{LOS TRES ASPECTOS DE "LA VIDA ES SUENTO"}

Analicemos ahora, sobre la base de este argumento (y dejando de lado la excelencia teatral, la calidad poética, y los méritos o las deficiencias de la forma), el pensamiento capital de este drama genial de Calderón.

\section{Biblioteca de Letras}

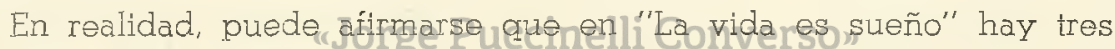
aspectos, cada uno de los cuales tiene su cabal expresión en determinados versos de la obra.

\section{EL A.SPECTO ESCEPTICO}

En primer lugar, el ilusionismo, el aspecto del engaño mañoso, del sueño y del fingimiento de la vida. Es, por cierto, un problema que no se origina en Calderón; sino que hunde sus raíces en los antiguos campos de las literaturas orientales. Investigándolo, tanto desde el punto de vista del fondo mismo cuanto de la forma como se ha llevado el tema al drama, los críticos han encontrado dos antecedentes o dos fuentes.

A) - En cuanto a la forma, el tema del hombre recluído en la cue$\mathrm{va}$ como consecuencia de un horóscopo adverso. El ejemplo seguido por Calderón se cree que puede hallarse en el célebre "Barlaam y Josafat", transformación cristiana de la leyenda de Buda, emparentada con el "Lalita Vistara" tibetano, y cuyo texto griego, de tan extraordinaria 
hace deli cuento no un motivo cómico sino una fuente de moralidad, como un ejemplo de los falaces engaños del mundo y la fugacidad de los goces terrenos. Con las palabras amargas del sabio libro, podría decirse también en este caso que todo pasa en la vida "como las nubes, como las naves, como las sombras". Arturo Farinelli ha seguido este dolido tema con detalle en diferentes literaturas, y de modo particular en la española. El despliegue es copioso; porque el regusto amargo de la vanidad de las pompas del mundo tiene, por otra parte, el halago especial y tentador de la fantasmagoría, muchas veces amable, de los sueños. Quizá la máxima ilusión, o por lo menos el mayor y más engañoso ejemplo de ilusión está en los sueños.

"¿Duermo o velo?", se preguntan diversos personajes; como el Don Carlos de la obra de Diego Ximénez de Enciso. Un paso más, y lo que era duda interrogante empieza a hacerse afirmación: la vida ES sueño. El concepto del sueño de la vida, se convierte en lugar común, en frase usual, en refrán, en proverbio. "Ser verdad aquel proverbio - de que es un sueñola vida", - afirma precisamente Calderón en "Las armas de la hermosura". Y la expresión definitiva, acierto de forma inigualado, la ofrece el soliloquio de Segismundo al terminar la segunda jornada de la comedia "La vida es sueño":

\footnotetext{
Es yerdad pues reprimamos esta fiera condíciónca de Letras esta furiar resta Pambición, li Converson por si alguna vez soñamos: y sí haremos, pues estamos en mundo tan singular, que el vivir sólo es soñar; y la experiencia me enseña que el hombre que vive, sueña lo que es, hasta dispertar.
}

Sueña el Rey que es Rey, y vive con este engaño mandando, disponiendo y gobernando; Y este aplauso, que recibe prestado, en el viento escribe; y en cenizas le convierte la muerte (jdesdicha fuerte!): ique hay qujen intente reinar, 
viendo que ha de dispertar

en el sueño de la muerte!

Sueña el rico en su riqueza, que más cuidados le ofrece; sueña el pobre que padece su miseria y su pobreza; sueña el que a medrar empieza, sueña el que afana y pretende, sueña el que agravia y ofende, y en el mundo, en conclusión, todos sueñan lo que son, aunque ninguno lo entiende.

Yo sueño que estoy aquí destas prisiones cargado, y soñé que en otro estado más lisonjero me ví.

¿Qué es la vida? Un frenesí. ¿Qué es la vicuá? Una ilusión, una sombra, una ficción,

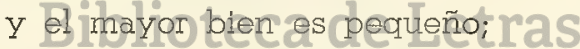
que toda la vida es pueño y los sueños sueños son.

\section{EL ASPECTO DOGMATICO}

Si toda la vida es sueño, ¿qué es lo que queda por hacer?. La desoladora conclusión parece que no puede ser otra que el escepticismo, la angustiosa insatisfacción, el desencanto; y, sobre todo, el concepto tremendo de la inutilidad de todo esfuerzo. El ilusionismo, de raíz oriental, se resuelve así en el concepto, también profundamente oriental, del nirvana. Si hay sólo apariencias falaces en las cosas, no queda sino el renunciamiento y el resignado naufragio en la ilusión. Todo empeño es en vano; y la única actitud consecuente y posible es la pasividad absoluta ante la grande y engañosa fantasmagoría del universo.

Este es, en realidad, el resultado inevitable del concepto oriental en su planteamiento más extremo. Pero el concepto cristiano de Calderón tenía que llevarlo a una conclusión muy diferente. Como ha observado Menéndez y Pelayo, la tesis escéptica del drama no es sino una preparación para la tesis dogmática que se plantea luego. Y esta dogmática 
afirmación estriba en que, si la vida no es al cabo sino un sueño engañoso, el verdadero despertar está en la muerte, en lo que llega después de la muerte. Allí, en esa supuesta sombra (que para los cristianos se halla encendida de fe), es donde terminan, paradójicamente, las auténticas sombras de la vida.

También en este caso, el pensamiento de Calderón de la Barca hun. de sus raíces en una concepción tradicional. Es, en tal hondo punto, la tradición filosófica cristiana, de tan copiosas y significativas manifestaciones en la literatura española de la Edad Media y la Edad de Oro, que exhoria a huir las sombras y las falacias del mundo engañador, para buscar en cambio la verdad profunda de ultratumba. Particularmente en los siglos XVI y XVII, son frecuentes las obras de títulos, de por si tan expresivos, como el "Tratado de la vanidad del mundo" de Diego de Estella, la "Diferencia entre-lo temporal y lo eterno, crisol de desen. gaños" del Padre Eusebio Nieremberg, o el exactísimo "Despertador del alma dormida para orar a Dios y despertar el hombre del sueño en que está" de Tuan González de Critana.

Con parejo criterio reacciona y se aclara Segismundo en el drama de Calderón. Si sé -- afirma en un aparte, en la tercera jornada de la obra -

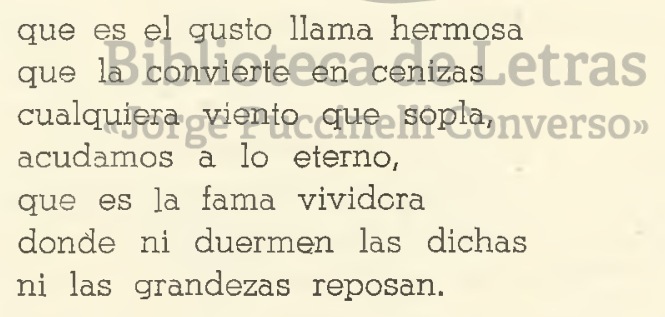

"Acudamos a lo eterno"; es decir, frente a lo perecedero, lo falso, lo engañoso, lo fantasmal de los bienes terrenos, proclama Segismundo la verdad permanente e inconmovible de ultratumba.

Donde se revela más claramente este contenido religioso del pensamiento de Don Pedro Calderón es en el auto' o, mejor dicho, los autos sacramentales que compuso con el mismo título de "La vida es sueño". El primero, que se publicó por primera vez hace veinte años, se halla más cerca de la comedia; hasta el punto de haberse considerado, aunque en verdad que con cierta imprecisión, como una versión de la comedia "a lo divino". Segismundo ya no es allí un hombre determinado, sino el Hombre; Basilio es el Verbo; Clotaldo, el Entendimiento; Clarín, el Albedrío. 
Fero hay un seyundo auto (de autenticidad, por lo demás, indiscutiblei. lo: que no ocurre con el anterior, cuya paternidad no ha sido probada por compieto), que constituye una ampliación y una refundición del: primero, y fué representado en 1673 e impreso en 1677, o sea en los últimos años de la vida de Calderón. Allí se mantienen, en la trama, algunos episodios de la comedia, compuesta cerca de cuarenta años antes; an 1635; lo que revela la continuidad del pensamiento y la persistencia dal problema en la mente de Calderón. El Hombre (o Segismundo) aparece también en la caverna, como una fiera y vestido de pieles. Dé allí lo sacan el Foder, la Sabiduría y el Amor (o sea, el Padre, el Hija $₹$ el Espíritu Santo, trifurcación del Verbo, que era un personaje única on el auto anterior), y lo conducen al Paraíso como Rey de la creación; de la misma manera que a Segismundo se le lleva al Palacio, coma hijo del Rey, en la comedia. Desatados sus ímpetus, dominada por sus instintos, el Hombre despeña al Entendimiento, como Segismundo arroja a un criado por el balcón en la comedia. Luego, en igual paralelismo, se producen la caída y el desengaño. Si Segismundo. vueive a la cueva en la comedia, el Hombre, en el auto sacramental, vuelve también a caer por el pecado. Es, en realidad, una triple culpa:. El falso hechizo del poder, el engañoso halago de la belleza y los sentidos, le han hecho pecar por la soberbia, por la vanidad y por la violencia lo sea, pedados Contra al (Peder, Eotntra Sa Sabiduría y contra el Ainor).

\section{"Jorge Puccinelli Converso"}

Pero en seguida se produce la regeneración. El Hombre (al fin y à. cabor, "auto sacramental"; es decir, drama alegórico religioso, con exaltación del dogma y el misterio aucarísticos) resulta redimido y levantado. por Cristo. El Hombre ha perdido un Paraíso de sueño y de engaño; paro por la intervención del Verbo hechc carne recobra luego un Paráse, no fingido ni falso, sino de verdad y de vida eterna.

El auto sacramental comienza así, en cierta manera, con un argumente semejante a la comedia; pero en seguida avanza por sus propios y prokundos senderos. Lo que en la comedia es el debate Sueño-Realidad, en el auto es la doble serie: Sombra-Luz, Caos-Orden, Cueva-Palacior, División-Unión, Odio-Amor, Pecado-Gracia. El auto sacramental "La. vida es sueño" es, de tal modo, una de las grandes producciones calderonianas sobre la Creación, el Pecado y la Redención, como "El venene y la triaca" o "El divino Orfeo", por ejemplo, que presentan, con galanura de poeta y con rigor de teólogo, el gran dogma católico de la Eucaristía, como coronación y culminación de la obra redentora de Cristo, en la tierra. 


\section{EL ASPECTO EJEMPLAR}

Dejemos, sin embargo, estos sublimes y lejanos terrenos. De la Creación, la Caída y la Redención, representados en el auto sacramental "La vida es sueño", volvamos a la cueva, la ascensión al Palacio y la recaída en la caverna del Príncipe Segismundo, hijo de Basilio, Rey de Polonia, en la comedia. Y entonces hallaremos también otra respuesta genial y afirmativa del insigne Don Pedro Calderón de la Barca. Como Menéndez Pelayo señalaba un primer aspecto escéptico y un segundo aspecto dogmático y trascendente, hay todavía un tercer aspecto, que se puede llamar ejemplar, de buen ejemplo, y que es el que otorga mayor fuerza, más real y palpitante tensión humana a la produccićn calderoniana. Si toda la vida es sueño, no hay siro que esperar a que se desvanezca. Si la verdad se encuentra más allá de la muerte, no hay sino que esperar también a que la muerte llegue.

Pero vivimos en la tierra, nos corresponde un período largo o corto en el vuelo del mundo. Y esta es la gran lección que se desprende del drama de Don Pedro Calderón: sin necesidad de esperar el otro mundo, tenemos que buscar en este mismo mundo algunas tablas de salvación a que aferrarnos. ¿Todo es de veras sueño, todo apariencia, todo engaño? Hay un instente expresivo en la comedia, cuando Segismundo afirma, en uno de los vaivenes apasionantes de su duda: "No

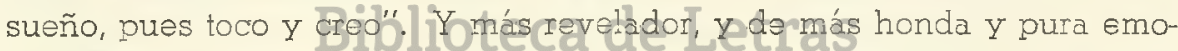
ción todavía, es el momento en el giye Segismundo, despierto de nuevo en la caverna, recuerda el encarto de Rosarra entre la bruma indecisa de su sueño, y exclama tiemamente:

Sólo a una mujer amaba;

que fué verdad, creo yo,

en que todo se acabó

y esto solo no se acaba.

Pero los sentidos y la emocićn personal son poca cosa; y se hallan siempre en peligro de engaño. En cambio, hay aigo más cierto, de lo que no sólo el propio Calderón, desde luego, sino su personaje Segismundo, no llegan al cabo a dudar nunca. En fin de cuentas, lo que es sueño en la vida es la gloria prestada, el poder efímero, la belleza fugaz. Mas debajo de la apariencia sensible de las cosas, del mundo de los fenómenos y de lo perecedero, hay otro mundo que es sustancial y permanente, que tiene autenticidad y consistencia; no sólo en lo ultraterreno, sino aún en esta misma vida. Es la sustancia de los grandes 
valores; el Bien, la propia verdad, la virtud, las Buenas Obras. Ellos existen, pese a todas las contingencias, y a todas las ilusiones y desilusiones de la vida. Y si en el auto sacramental el Hombre recupera su Entendimiento y por la Gracia de Dios vuelve a ganar el Paraíso, en la comedia "La vida es sueño" el Príncipe Segismundo reflexiona, comprende que las circunstancias "sólo el albedrío inclinan, no fuerzan el albedrío", y tiempla sus pasiones, para levantarse racional y seguro, vencedor de sí miemo, que - como en la frase profunda del "Quijote" - es el mayor vencimiento que desearse pueda.

Entre el sueño de la vida y la verdad ulterior de lo eterno, está la propia verdad terrena, no tan inestable ni tan ficticia. Y si el aspecto esceptico se hallaba representado en una frase: "todos sueñan lo que son, aunque ninguno lo entiende"; si el aspecto dogmático llegaba al imperativo "acudamos a lo eterno"; este tercer aspecto, ejemplar, recomienda ante todo el obrar bien. "Obrar bien es lo que importa, - para cuando despertemos".

\section{LA TRADICION ESPANTOLA}

En esto también, la obra genial de Calderón se enlaza con la gran tradición del pensamiento y del espíritu de España. Singular en su concepción, personalísimo en su desarrollo, el drama "La vida es sueño" hunde así sus raíces êl lós estratos más profundos no sólo de las manifestaciones culturales, sino del propio y auténtico espíritu español. Porque ese espiritu, idealista sumpre en el impulso y y siempre elevado en la misión, no ofrece - aun cuando a veces así se haya dicho, erradamente - un desasimiento de las cosas terrenas. Nada más alejado de la realidad que los engañosos "castillos en España", que es la versión francesa de nuestros "castillos en el aire". Los castillos de España tienen carácter real, contextura tangible, hasta sentido práctico.

"Obras, obras", pedía la propia genial mística Santa Teresa de Jesús, mujer inquieta y andariega, de afanes celestiales y cuidados terrenos, que si creía morir por no morir y se estremecía al sentirse como envuelta en la túnica tibia y roja de la sangre de Cristo, también barría celdas y fundaba conventos: hasta el punto de que el dominico Padre Hernández llegaba a afirmar de ella: "esta no es mujer, sino hombre barbado".

Obras, obras, realiza asimismo el gran asceta Ignacio de Loyola, que quería forjar la perfección del hombre con ejercicios espirituales, y que no fundó una legión contemplativa sino una combativa y resuelta milicia: la Compañía de Jesús. (Milicia catequista, solamente. Porque, de 
la otra milicia, ya el cielo de España había visto cruzar muchas veces, la capa al viento y el corcel impetuoso, al Apóstol Santiago "Matamoros $\left.{ }^{\prime \prime}\right)$.

En el terreno literario, el egregio Miguel de Cervantes junta también realísmo e idealismo, y nos da la gran lección afirmativa de su obra maestra, al enseñarnos que el hombre debe hallarse siempre listo como Don Quijote - a lanzarse a lo alto, pero - como Sancho Panza debe también hundir, realistamente, su raíz en la tierra.

Y hasta Jorge Manrique, en las inmortales "Coplas" a la muerte de su padre, si afirma, con cierto sabor de Eclesiastés, que "nuestras vidas son los ríos que van a dar a la mar que es el morir", señala al propio tiempo, junto a la vanidad de las cosas terrenas y la perduración de la vida celeste, una tercera vida: la terrena y honrosa de la fama (o sea, la conquistada por los hechos), que no es la eternal y verdadera,

\section{mas con todo es muy mejor}

que la otra temporal

perescedera.

Así lo proclama igualmente Calderón con la enseñanza de "La vida es sueño". Son sueños la gloria, la riqueza, el dominio imperial, el poderío, (que, de otrobàdo] lentla Españaedel sígloaXVII empezaban también a desmedrarse). Pere, pen cambio hay otros valores que son ciertos, y que - a hombres como a pueblos - deben conducimos, como cabal consecuencia, a obrar bien; "que es siempre lo más seguro - para cuando despertemos'.

Honremos, por lo tanto, a esta alta cumbre del espíritu, a este insigne Don Pedro Calderón de la Barca, digno, solemne, afirmativo, español y universal al propio tiempo, que se esforzó por enseñarnos, con su pensamiento y con su obra, qué es el sueño ficticio y qué es la esencia profunda de la vida. 